\title{
Effect of Half and Whole Root Drying on Photosynthesis, Nitrate Concentration, and Nitrate Reductase Activity in Roots and Leaves of Micropropagated Apple Plants
}

\author{
Jun Ying Zhao, Li Jun Wang, Pei Ge Fan, Zhan Wu Dai, and Shao Hua Li ${ }^{1}$ \\ Institute of Botany, Chinese Academy of Sciences, 100093 Beijing, China
}

\begin{abstract}
AdDitional INDEX wORDs. Malus $\times$ domestica, drought stress, polyethylene glycol, leaf water potential, stomatal conductance, transpiration rate, ammonium ion

Abstract. Half or whole root systems of micropropagated ' Gala' apple (Malus $\times$ domestica Borkh.) plants were subjected to drought stress by regulating the osmotic potential of the nutrient solution using polyethylene glycol $(20 \% \mathrm{w} / \mathrm{v})$ to investigate the effect of root drying on $\mathrm{NO}_{3}^{-}$content and metabolism in roots and leaves and on leaf photosynthesis. No significant difference in predawn leaf water potential was found between half root stress (HRS) and control (CK), while predawn leaf water potential from both was significantly higher than for the whole root stress (WRS) treatment. However, diurnal leaf water potential of HRS was lower than CK and higher than WRS during most of the daytime. Neither HRS nor WRS influenced foliar $\mathrm{NO}_{3}$ - concentration, but both significantly reduced $\mathrm{NO}_{3}$ - concentration in droughtstressed roots as early as 4 hours after stress treatment started. This reduced $\mathrm{NO}_{3}$ - concentration was maintained in HRS and WRS roots to the end of the experiment. However, there were no significant differences in $\mathrm{NO}_{3}$ - concentration between CK roots and unstressed roots of $\mathrm{HRS}$. Similar to the effect on root $\mathrm{NO}_{3}$ - concentration, both $\mathrm{HRS}$ and WRS reduced nitrate reductase activity in drought-stressed roots. Moreover, leaf net photosynthesis, stomatal conductance and transpiration rate of HRS plants were reduced significantly throughout the experiment when compared with CK plants, but the values were higher than those of WRS plants in the first 7 days of stress treatment though not at later times. Net photosynthesis, stomatal conductance and transpiration rate were correlated to root $\mathrm{NO}_{3}$ - concentration. This correlation may simply reflect the fact that water stress affected both $\mathrm{NO}_{3}$-concentration in roots and leaf gas exchange in the same direction.
\end{abstract}

Localized irrigation, which includes drip irrigation and micro-sprinkling, is widely used for irrigation management in fruit production throughout the world. The responses of fruit trees to localized irrigation were largely studied in the field, specifically focusing on photosynthesis, vegetative growth, cropping and fruit quality (Bryla et al., 2003; Li et al., 1989; Punthakey, 1984; Zhu et al., 2004). Leaf photosynthesis of fruit trees, such as 'Redchief Delicious' apple (Xu, 1999), was generally higher under localized irrigation than under flood irrigation. Stomatal conductance $\left(g_{\mathrm{s}}\right)$, transpiration rate $(\mathrm{Tr})$, and vegetative growth decreased significantly under drip irrigation or micro-sprinkling when compared with flood irrigation (Bryla et al., 2003; Punthakey, 1984). However, fruit growth rate, size, quantity, and quality do not decrease under localized irrigation, and they may be improved (Davies et al., 2000; Loveys et al., 2000).

Nitrogen nutrition plays an important role in vegetative growth and fruit quality of fruit trees. Severe drought affects not only $\mathrm{NO}_{3}$ availability at the root surface, but also the physiological capacity for root $\mathrm{NO}_{3}^{-}$uptake (Buljovcic and Engels, 2001). Moreover, evidence from other species showed that the sensitivity of $g_{\mathrm{s}}$ to $\mathrm{N}$ nutrition varied under different water conditions (Shangguan et al., 2000). In several prairie grasses, a close correlation existed between foliar $\mathrm{N}$ concentration and photosynthesis in response to water stress and recovery once water was restored (Heckathorn

Received for publication 27 Apr. 2006. Accepted for publication 17 July 2006. This study was made possible by funding from the National Natural Science Foundation of China (30370986). We would like to thank Prof. Douglas D. Archbold, Univ. of Kentucky, for critical review of the manuscript.

${ }^{1}$ Corresponding author: e-mail:shhli@ibcas.ac.cn; phone: 86-10-62836026; fax: 86-10-62836026. et al., 1997). Study of sunflower (Helianthus annuus L.) revealed that root $\mathrm{NO}_{3}{ }^{-}$concentration decreased during soil drying (Correia et al., 2005). Usually, nitrate reductase [NR (EC 1.6.6.1)] activity decreases when plants are subjected to drought stress (Azedo-Silva et al., 2004; Chandrasekar et al., 2000; Foyer et al., 1998). Though $\mathrm{NO}_{3}$ - acts as substrate and signal molecule in the N metabolic pathway (Foyer and Noctor, 2002; Gawronska et al., 2003; Goupil et al., 1998; Parsons and Sunley, 2001; Scheible et al., 1997; Tischner, 2000), very little attention has been paid to the contribution of drought-induced $\mathrm{NO}_{3}$ - changes to photosynthesis, especially in fruit trees under partial root zone drying.

The effect of drought-induced $\mathrm{NO}_{3}$ - change and its relationship to photosynthesis in fruit trees under localized irrigation has been largely ignored due to the large plant size of fruit trees and the heterogeneity of water conditions in the field and in pots. Since the osmotic potential of aqueous solutions of polyethylene glycol (PEG) was related to PEG concentration and was mainly changed with temperature variation (Michel and Kaufmann, 1973), the use of PEG solutions to simulate water deficits on micropropagated plants can create uniform drought stress conditions to roots. The entire root zone is not uniformly wetted when water is provided under localized irrigation; rather, only a part of root system of the tree gets water while the other roots are still subjected to drought stress throughout the growing season in arid and semiarid regions. This soil water condition can be simulated by a split root technique (Loveys et al., 2000). The objective of the present study was to use the split root techniques to define the effect of drought stress applied to half of the root system to simulate the condition of trees under localized irrigation versus drought stress applied to the whole root system of micropropagated apple plants 
on $\mathrm{NO}_{3}{ }^{-}$and $\mathrm{NH}_{4}{ }^{+}$concentrations in the roots and leaves and on photosynthesis. In addition, the relationship between droughtinduced $\mathrm{NO}_{3}$ - change to photosynthesis was investigated.

\section{Materials and Methods}

Plant materials and experimental conditions. Micropropagated 'Gala' apple plants were grown in plastic pots containing culture media of 1 vermiculite $: 3$ peat : 6 field soil (by volume) in a greenhouse for 1 year. Two well-developed buds were kept on each trunk at winter pruning, and one new shoot was kept after bud break in early spring. When the new shoots reached a length of $\approx 20 \mathrm{~cm}$, a uniform set of 16-month-old plants were repotted into black glass containers $(15 \times 20 \times 80 \mathrm{~cm}$, with two independent compartments of equal volume) containing modified Hoagland nutrient solution. The solution contained $0.5 \mathrm{~mm} \mathrm{KNO}, 0.3 \mathrm{~mm}$ $\mathrm{Mg}\left(\mathrm{NO}_{3}\right)_{2}, 0.11 \mathrm{~mm} \mathrm{Ca}\left(\mathrm{NO}_{3}\right)_{2}, 0.5 \mathrm{mM} \mathrm{CaCl}_{2}, 0.5 \mathrm{mM} \mathrm{MgSO}_{4}, 0.5$ $\mathrm{mm} \mathrm{KH}_{2} \mathrm{PO}_{4}, 3.9 \mu \mathrm{M} \mathrm{ZnSO}_{4}, 2.6 \mu \mathrm{M} \mathrm{CuSO}_{4}, 4.6 \mu \mathrm{M} \mathrm{MnCl}_{2}, 0.44$ $\mu \mathrm{M}$ EDTA.Fe' Na, $0.25 \mu \mathrm{M} \mathrm{H}_{3} \mathrm{BO}_{3}$, and $0.33 \mathrm{~nm}\left(\mathrm{NH}_{4}\right)_{6} \mathrm{Mo}_{7} \mathrm{O}_{24}$. Roots of each plant were washed before putting in the container and were divided equally into the two compartments. The glass containers were covered with wooden boards to maintain a dark environment for the roots, and the nutrient solutions were aerated continuously. The plants were grown under ambient conditions at $20-32^{\circ} \mathrm{C}$ and a $17-\mathrm{h}$ photoperiod of natural light.

Treatments. When plants were about $25 \mathrm{~cm}$ in height with 10 mature leaves, after $20 \mathrm{~d}$ in the nutrient solution, treatments were initiated. Half root stress or whole root stress treatments were imposed starting at 0600 HR on the morning on 4 May 2004, and were compared with a control. HRS and WRS were applied by regulating the osmotic potential of the solution using $20 \%$ w/v PEG (PEG-6000; Wako Pure Chemical Industries, Osaka, Japan), which corresponds osmotic potential of $-0.511 \mathrm{MPa}$ at $25^{\circ} \mathrm{C}$ based on the calculation formula of Michel and Kaufmann (1973). For HRS, one compartment of the glass container was filled with modified Hoagland solution containing 20\% PEG6000 and the other one received regular solution. For WRS, both compartments were filled with Hoagland solution containing $20 \%$ PEG-6000. For CK, both compartments were filled with regular Hoagland solution. The nutrition solution was replaced at 0600 HR on day 4 and day 7 after starting the treatments. There were four replications of each treatment with 60 plants per replication, 30 of which were used for $\mathrm{NO}_{3}{ }^{-}, \mathrm{NH}_{4}{ }^{+}$, and other biochemical analyses, and 30 were used for leaf water potential and photosynthesis measurements. Plants were arranged in a completely randomized design in the greenhouse.

Measurements of Leaf water potential. Predawn and diurnal variation in leaf water potential was determined from two fully expanded mature leaves per plant from the middle of the shoot (Scholander et al., 1964). Measurements were made on one plant from each replication on each sampling date using a pressure chamber (ZLZ-4; Lanzhou Univ., Lanzhou, China). Diurnal variation of leaf water potential was measured on the fifth day after initiating treatments.

LEAF AND ROOT SAMPLING FOR BIOCHEMICAL ANALYSIS. Welldeveloped leaves and fine roots were harvested from five plants per replication of each treatment on the day prior to starting the experiment, and around $1000 \mathrm{HR}$ at 1 (i.e., $4 \mathrm{~h}$ ), 2, 4, 7, and 11 $\mathrm{d}$ after starting drought stress treatments. All the sample tissues were rinsed thoroughly in tap water first and then again in deionized water to remove attached PEG-6000 or unabsorbed nutrition salts. The clean samples were blotted dry with paper towels and immediately frozen in liquid nitrogen. Then, they were pooled and ground to fine powder in liquid nitrogen and stored at -80 ${ }^{\circ} \mathrm{C}$ until used for biochemical analyses.

DETERMINATION OF $\mathrm{NO}_{3}^{-}, \mathrm{NH}_{4}^{+}$, FREE AMINO ACID, AND PROLINE CONCENTRATIONS. To determine $\mathrm{NO}_{3}{ }^{-}$and $\mathrm{NH}_{4}{ }^{+}$concentrations, $1.0 \mathrm{~g}$ of the leaf or root powder was homogenized with $10 \mathrm{~mL}$ double distilled water together with polyvinylpyrrolidone in a mortar precooled by liquid nitrogen (Jiang et al., 2003). The homogenates were extracted under ultrasonic conditions at $4{ }^{\circ} \mathrm{C}$ for $30 \mathrm{~min}$ and then centrifuged for $10 \mathrm{~min}$ at $4{ }^{\circ} \mathrm{C}$ and $18,000 \mathrm{~g}_{\mathrm{n}}$. Then, the supernatants were passed through a Supelclean ENVICarb SPE column (Sigma-Aldrich Corp., St. Louis). Thereafter, $\mathrm{NO}_{3}{ }^{-}$in the effluent was determined by ion exchange chromatography (DX-600; Dionex Corp., Sunnyvale, Calif.) using an IonPacAS11 column (Dionex Corp.) with a solution containing $50 \mathrm{~mm} \mathrm{NaOH}$ and detected with a conductivity detector module (ED50; Dionex Corp.). The same supernatant was used for $\mathrm{NH}_{4}{ }^{+}$ determination by the same ion exchange chromatography using an IonPacCS12A column (Dionex Corp.) with a solution containing $20 \mathrm{~mm}$ methanesulfonic acid and detected by the same conductivity detector module.

Total free amino acids were extracted and quantified as follows: $0.3 \mathrm{~g}$ of frozen sample was boiled in $10 \mathrm{~mL}$ deionized water for $30 \mathrm{~min}$, centrifuged for $20 \mathrm{~min}$ at $20,000 \mathrm{~g}_{\mathrm{n}}$, and the supernatant was collected. The residue was washed and centrifuged twice with $10 \mathrm{~mL}$ deionized water. The supernatants were combined and made up to $50 \mathrm{~mL}$ with distilled water. Total free amino acids were determined spectrophotometrically using the ninhydrin method described by Tang (1999).

Determination of proline content was according to methods described by Bates et al. (1973). Frozen leaf sample of $1.0 \mathrm{~g}$ was homogenized with $10 \mathrm{~mL}$ of $3 \%$ sulfosalicylic acid (w/v) and boiled for $10 \mathrm{~min}$. Then, the homogenates were centrifuged at $3000 g_{n}$ for $20 \mathrm{~min}$ and the supernatants were collected for proline content determination. The reaction mixture contained $1.2 \mathrm{~mL}$ of the supernatant, $2 \mathrm{~mL}$ of glacial acetic acid, and $3 \mathrm{~mL}$ of $2.5 \%$ acid ninhydrin, and was boiled for $40 \mathrm{~min}$. After termination of the reaction in an ice bath, the reaction mixture was extracted by $5 \mathrm{~mL}$ toluene and the absorbance was determined at $520 \mathrm{~nm}$.

NR ACTIVITY. To prepare the enzyme extracts, $1.0 \mathrm{~g}$ of frozen root sample was extracted with $25 \mathrm{~mm}$ phosphate buffer $(\mathrm{pH} 7.5)$ containing $5 \mathrm{~mm}$ L-cysteine and $5 \mathrm{~mm}$ EDTA-Na $\mathrm{Na}_{2}$ in a mortar precooled with liquid nitrogen. After rapid homogenization while ice-cold, the homogenates were centrifuged for $10 \mathrm{~min}$ at $4{ }^{\circ} \mathrm{C}$ and $12,000 g_{n}$, and then dialyzed at $4{ }^{\circ} \mathrm{C}$ by stirring against 0.067 M phosphate buffer ( $\mathrm{pH} 7.5$ ) for $48 \mathrm{~h}$ (Grasmanis and Nicholas, 1967). Thereafter, NR activity was measured immediately in the supernatant according to methods described previously (Tang, 1999). The reaction mixture contained $1.2 \mathrm{~mL}$ of $0.1 \mathrm{M} \mathrm{KNO}_{3}$, $0.4 \mathrm{~mL}$ of $2.5 \mathrm{~mm} \mathrm{NADH}_{2}$ in phosphate buffer $(\mathrm{pH} 7.5)$ and 0.4 $\mathrm{mL}$ of extract. The reactions proceeded at $30{ }^{\circ} \mathrm{C}$ for $30 \mathrm{~min}$, and were then stopped by adding $1 \mathrm{~mL}$ of $1 \%$ sulfanilamide in $3 \mathrm{M} \mathrm{HCl}$. Thereafter, $0.2 \%$ 1-naphthylamine was added and the mixture was centrifuged $20 \mathrm{~min}$ at $1000 \mathrm{~g}_{\mathrm{n}}$ for $5 \mathrm{~min}$. The absorbance was determined at $540 \mathrm{~nm}$. NR activity was defined as amount (micrograms) of $\mathrm{NO}_{2}$ - produced per milligram protein. The content of soluble protein was determined by the Bradford protein assay (Bradford, 1976).

Measurements of net Photosynthesis (Pn) AND Related PARAMETERS. Net photosynthesis and related photosynthetic parameters of fully expanded leaves were measured between 0830 to 1100 HR on all sunny days throughout the experiment. 
Measurements were performed on three randomly selected plants in each replication using a portable photosynthesis system (LCA4; ADC, Hoddesdon, U.K.).

Statistical analysis. All statistical analyses was performed using the SPSS statistical package (version 11.0; SPSS Inc., Chicago). Moreover, correlations between $\mathrm{NO}_{3}{ }^{-}$concentration in leaves and roots and photosynthesis or the other photosynthetic parameters were determined. Only the data obtained from CK, WRS, and stressed roots of HRS were used for the regression analyses concerning $\mathrm{NO}_{3}$ - concentration in roots.

\section{Results}

Leaf Water potential. Predawn leaf water potential $\left(\Psi_{\text {pd }}\right)$ of CK was nearly constant at a high level $(-0.36$ to $-0.22 \mathrm{MPa})$ throughout the experiment, and no significant difference in $\Psi_{\mathrm{pd}}$ was found between HRS and CK (Fig. 1A). However, $\Psi_{\mathrm{pd}}$ of WRS was significantly lower than CK and HRS starting on day 2 after plants were subjected to drought stress. The $\Psi_{\text {pd }}$ of WRS plants decreased gradually to $-1.2 \mathrm{MPa}$ until $8 \mathrm{~d}$ after starting treatments, and stayed at about $-1.0 \mathrm{MPa}$ to the end of the experiment (Fig. 1A).

The diurnal variation in leaf water potential $\left(\Psi_{\mathrm{d}}\right)$ is shown in Fig. 1B. It declined rapidly in the morning in all treatments, reached the lowest value at about $1000 \mathrm{HR}$, and slowly recovered in the afternoon. There were significant differences between treatments, especially from 1000 to $1900 \mathrm{HR}$. The $\Psi_{\mathrm{d}}$ from HRS plants was significantly lower than CK, but higher than WRS during most of daytime. While $\Psi_{\mathrm{d}}$ of CK and HRS had recovered fully by $2300 \mathrm{HR}, \Psi_{\mathrm{d}}$ of WRS was still significantly lower than CK and HRS.

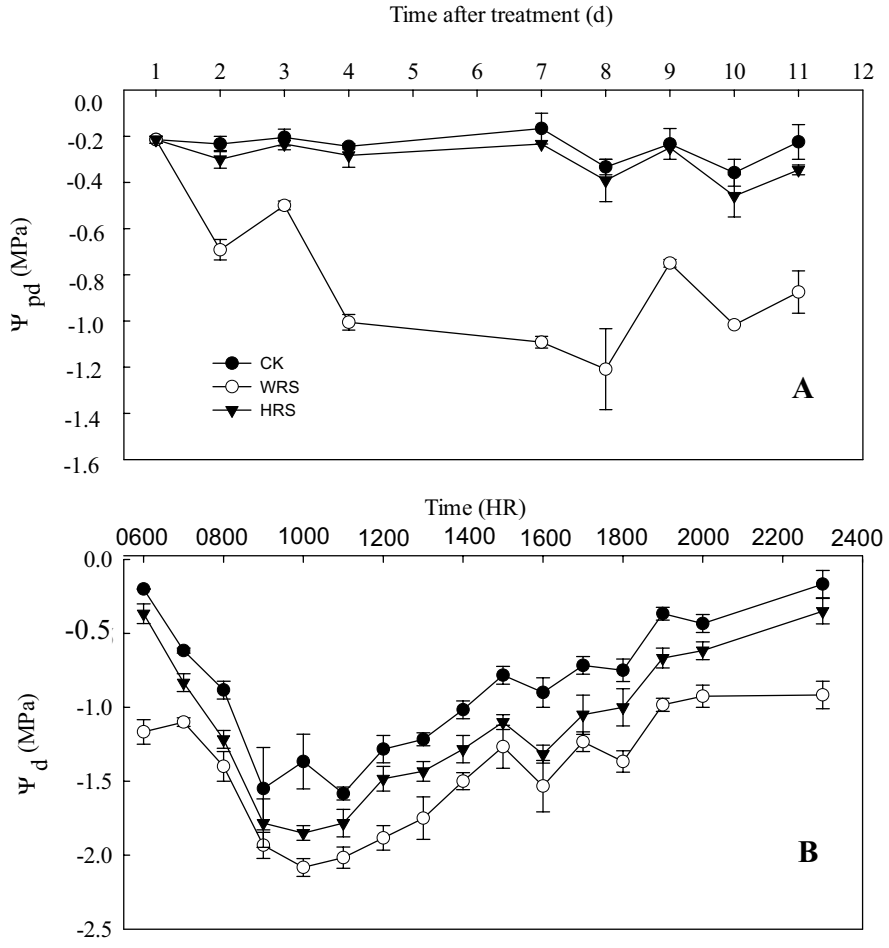

Fig. 1. Response of predawn leaf water potential $\left(\psi_{\mathrm{pd}}\right)$ throughout the experiment $(\mathbf{A})$ and diurnal leaf water potential $\left(\psi_{\mathrm{d}}\right)$ on the fifth day after initiating treatments $(\mathbf{B})$ of micropropagated apple plants to half root drought stress (HRS) and whole root drought stress (WRS) when compared with control $(\mathrm{CK})$. Each point is mean $\pm \operatorname{SE}(n=4)$.
$\mathrm{NO}_{3}^{-}$CONCENTRation aNd NR aCtivity. Similar tendency of change in foliar $\mathrm{NO}_{3}$ - concentration of HRS and WRS to CK throughout the experiment was obtained in this study (Fig. 2A). The lowest and highest foliar $\mathrm{NO}_{3}$ - concentration were observed on both stressed treatments and CK on day 2 and 7, respectively. However, foliar $\mathrm{NO}_{3}{ }^{-}$concentration was very low, 4.3 to 23.6 $\mu \mathrm{g} \cdot \mathrm{g}^{-1}$, for all treatments when compared with roots and there were no significant differences in foliar $\mathrm{NO}_{3}$ - concentration among CK, HRS, and WRS throughout the experiment, indicating that drought stress had no effect on foliar $\mathrm{NO}_{3}$ - concentration.

In contrast, both HRS and WRS had marked effects on root $\mathrm{NO}_{3}$ - concentration (Fig. 2B). Nitrate concentration in the stressed

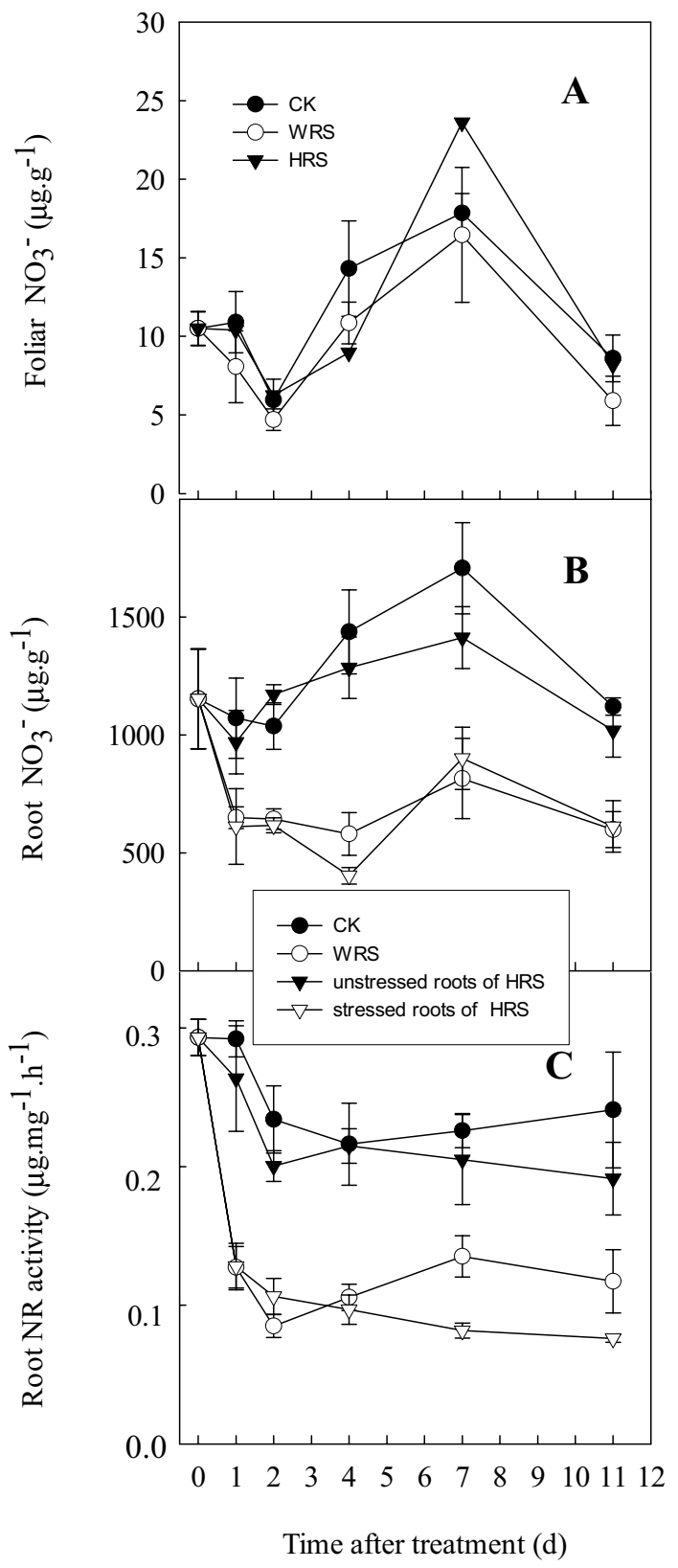

Fig. 2. Nitrate concentration in leaves $(\mathbf{A})$ and roots $(\mathbf{B})$, and nitrate reductase (NR) activity in roots $(\mathbf{C})$ of micropropagated apple plants under half root drought stress (HRS) and whole root drought stress (WRS) when compared with control (CK). Nitrate concentration is expressed on a fresh weight basis and NR activity is defined as amount $(\mu \mathrm{g})$ of $\mathrm{NO}_{2}$ - produced per milligram protein. Each point is mean \pm $\mathrm{SE}(\mathrm{n}=4)$. 
roots of WRS and HRS decreased to about $50 \%$ of CK, significantly lower as early as the day 1 , within $4 \mathrm{~h}$ after treatments were initiated. This decreased $\mathrm{NO}_{3}^{-}$concentration was maintained in the stressed roots of WRS and HRS to the end of the experiment. However, there was no significant difference in $\mathrm{NO}_{3}$ - concentration between $\mathrm{CK}$ roots and unstressed roots of HRS.

Similar to the effect on root $\mathrm{NO}_{3}$ - concentration, both HRS and WRS reduced root NR activity (Fig. 2C). Root NR activity declined to $32 \%-46 \%$ and $36 \%-60 \%$ of CK in stressed roots of HRS and WRS, respectively. However, NR activity in unstressed roots of HRS remained at a level similar to CK. Moreover, a significant quadratic correlation was found between NR activity and $\mathrm{NO}_{3}{ }^{-}$concentration (Fig. $3, r^{2}=0.638, P<0.001$ ).

$\mathbf{N H}_{4}{ }^{+}$Concentration. Drought stress had no effect on foliar $\mathrm{NH}_{4}{ }^{+}$concentration when compared with $\mathrm{CK}$ (Fig. 4A), while $\mathrm{NH}_{4}{ }^{+}$concentration in stressed roots of HRS and WRS treatments increased markedly $7 \mathrm{~d}$ after plants were subjected to drought stress, and rose to 2.7-fold and 2.2-fold of CK values by the end of experiment, respectively (Fig. 4B). However, $\mathrm{NH}_{4}{ }^{+}$concentration was not altered in unstressed roots of HRS, and there were no significant difference in $\mathrm{NH}_{4}{ }^{+}$concentration between $\mathrm{CK}$ and unstressed roots of HRS throughout the experiment.

Pn, gs, AND Tr. Drought stress applied to both half and whole root systems influenced $\mathrm{Pn}, \mathrm{g}_{\mathrm{s}}$, and Tr of micropropagated apple plants (Fig. 5A-C). HRS resulted in between $30 \%$ to $74 \%$ lower $\mathrm{Pn}, 25 \%$ to $54 \%$ lower $\mathrm{g}_{\mathrm{s}}$, and $48 \%$ to $62 \%$ lower $\mathrm{Tr}$ compared to $\mathrm{CK}$ plants. However, Pn, $\mathrm{g}_{\mathrm{s}}$, and Tr were significantly higher in HRS than those in WRS during days 1-7, though there was no significant difference between HRS and WRS thereafter.

Free AMINo ACID AND PROLINE CONCENTRATION. The effect of HRS on foliar free amino acid concentration varied throughout experiment. Significantly lower foliar free amino acid concentration was observed from HRS plants than CK on days 4 and 7 after initiating water stress. However, there were no significant difference between HRS and CK for the other days (Fig. 6A). As regards WRS, significantly increased foliar free amino acid concentration was observed only on day 11 when compared with CK.

A dramatic increase in foliar proline concentration was found in plants receiving WRS from day 2 after starting the treatment (Fig. 6B). It increased by 1.4 -fold on day 2 and by 2.6-fold on day 11 when compared with CK. Foliar proline concentration of HRS plants did not differ from CK plants throughout the experiment (Fig. 6B).

CORRELATIONS BETWEEN NO $\mathrm{NO}_{3}^{-}$CONCENTRATION AND PHOTOSYNTHESIS. A significant quadratic correlation was found between Pn and $\mathrm{NO}_{3}{ }^{-}$concentration in roots (Fig. 7A). Net photosynthesis increased sharply with $\mathrm{NO}_{3}{ }^{-}$concentration in roots until $\mathrm{NO}_{3}$ concentration in roots was above $1200 \mu \mathrm{g} \cdot \mathrm{g}^{-1}$. Moreover, $\mathrm{g}_{\mathrm{s}}$ and Tr were linearly correlated with $\mathrm{NO}_{3}$ - concentration in roots (Fig. 7B and C). However, no significant correlation was found between foliar $\mathrm{NO}_{3}{ }^{-}$concentration and $\mathrm{Pn}, \mathrm{g}_{\mathrm{s}}$, and $\mathrm{Tr}$, respectively (data not shown).

\section{Discussion}

The foliar $\mathrm{NO}_{3}$ - concentration was extraordinarily low when compared with that in roots of both drought-stressed and control apple plants in this study (Fig. 2). This differs from herbaceous plants such as maize (Zea mays L.), wheat (Triticum aestivum L.), and lettuce (Lactuca sativa L.), which have shown higher foliar $\mathrm{NO}_{3}$ - concentrations (Correia et al., 2005; Ferrario-Méry et al.,

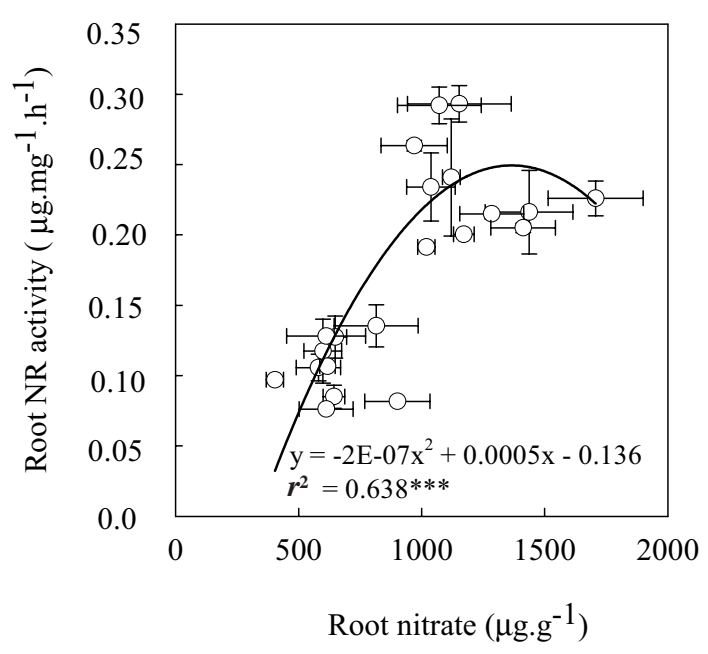

Fig. 3. Correlation between root nitrate reductase (NR) activity and $\mathrm{NO}_{3}$ concentration of micropropagated apple plants under control, whole root drought stress and half root drought stress. Nitrate concentration is expressed on a fresh weight basis and NR activity is defined as amount $(\mu \mathrm{g})$ of $\mathrm{NO}_{2}{ }^{-}$produced per milligram protein. Each point is mean $\pm \mathrm{SE}$ $(\mathrm{n}=4)$. The asterisks $* * *$ indicate significance at 0.001 .

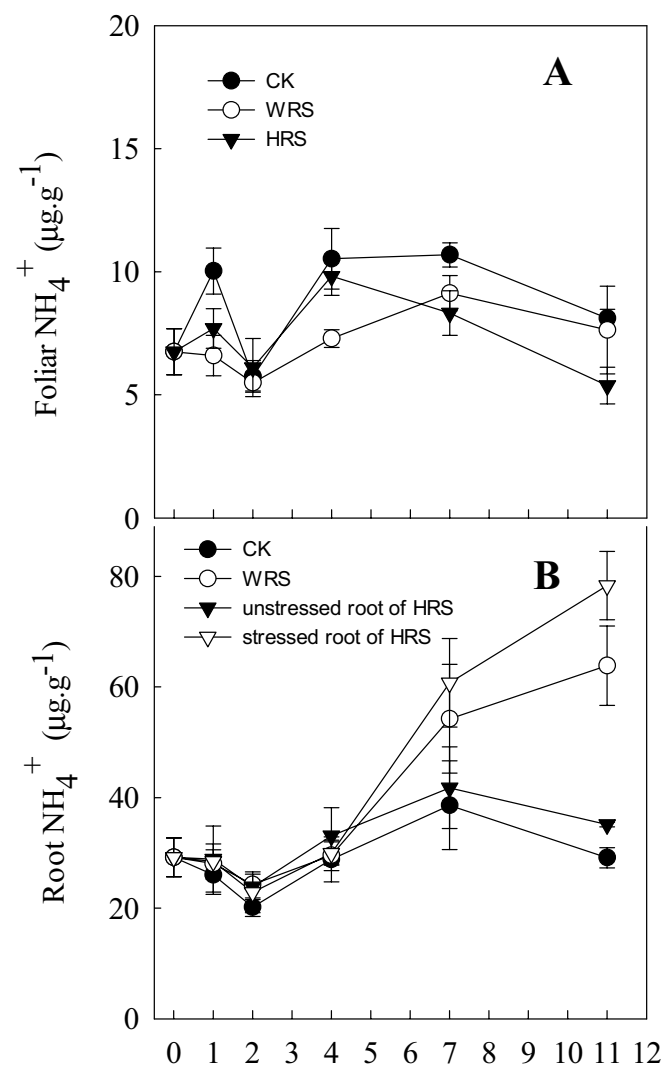

Time after treatment (d)

Fig. 4. Ammonium concentration in leaves (A) and roots (B) of micropropagated apple plants under half root drought stress (HRS) and whole root drought stress (WRS) when compared with control (CK). Ammonium concentration is expressed on a fresh weight basis. Each point is mean $\pm \operatorname{SE}(n=4)$. 


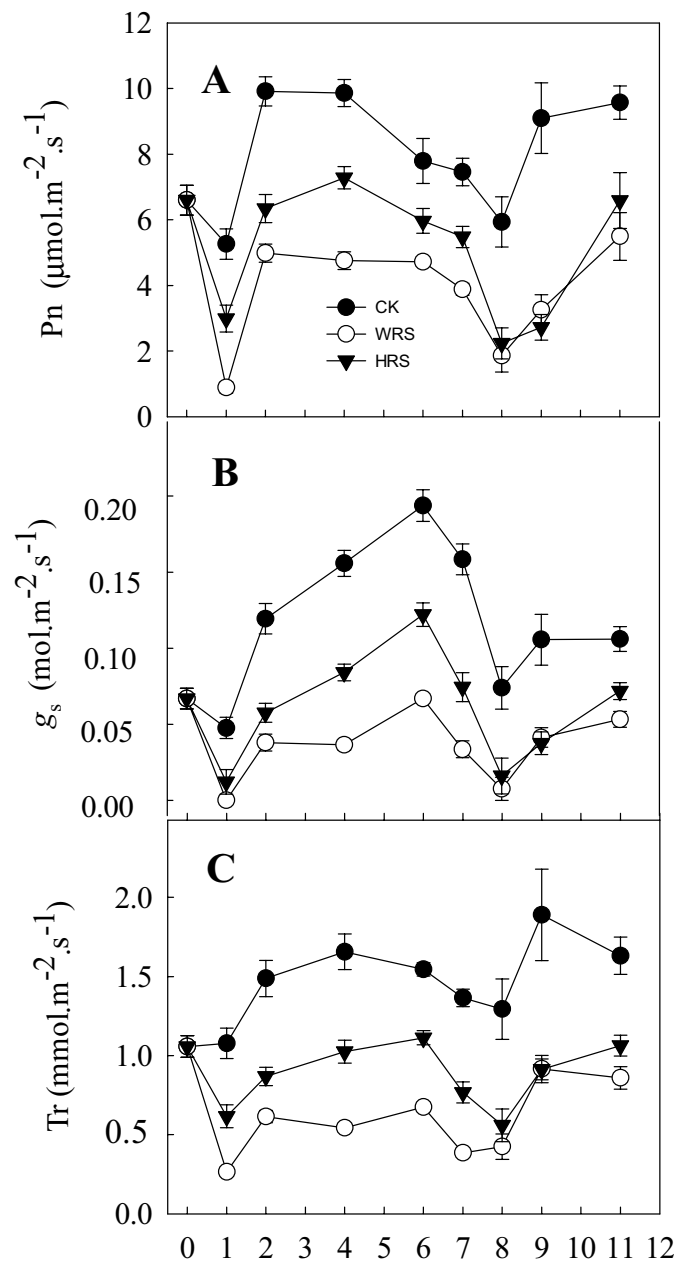

Time after treatment (d)

Fig. 5. Leaf net photosynthesis $(\mathrm{Pn})(\mathbf{A})$, stomatal conductance $\left(\mathrm{g}_{\mathrm{s}}\right)(\mathbf{B})$, and transpiration rate $(\operatorname{Tr})(\mathbf{C})$ of micropropagated apple plants under half root drought stress (HRS) and whole root drought stress (WRS) when compared with control $(\mathrm{CK})$. Each point is mean $\pm \mathrm{SE}(\mathrm{n}=4)$.

1998; Foyer et al., 1998). In these species, $\mathrm{NO}_{3}^{-}$can accumulate to a high concentration in the vacuoles of leaf cells as a result of the shortage of carbon skeletons for synthesis of nitrogen-containing organic compounds (Demšar et al., 2004). Prior studies also showed that $\mathrm{NO}_{3}^{-}$- was very low in parts of the apple plant other than roots (Lee and Titus, 1992). It seems that absorbed $\mathrm{NO}_{3}{ }^{-}$is mainly reduced in the roots of apple trees.

Drought stress from both HRS and WRS treatments influenced $\mathrm{NO}_{3}$ - concentration in the roots. Root $\mathrm{NO}_{3}$ - concentration only decreased in drought-stressed roots (Fig. 2B). Low $\mathrm{NO}_{3}^{-}$ concentration was accompanied by low NR activity in the roots under drought stress (Fig. 2C). Regression analyses showed that there was a significant correlation between NR activity and $\mathrm{NO}_{3}$ - concentration in roots (Fig. 3). In maize leaves, decreased $\mathrm{NO}_{3}-$ may lead to a decrease in quantity of NR mRNA (Foyer et al., 1998). The decrease of root NR activity observed following the onset of drought stress in this study could have been caused by the decrease in root $\mathrm{NO}_{3}$ - The latter would directly result from a decrease in $\mathrm{NO}_{3}{ }^{-}$absorption ability of the stressed roots (Ferrario-Méry et al., 1998).

Stomata closure, decline in Pn, accumulation of carbohydrates, and changes in activities of related carbon metabolic enzymes

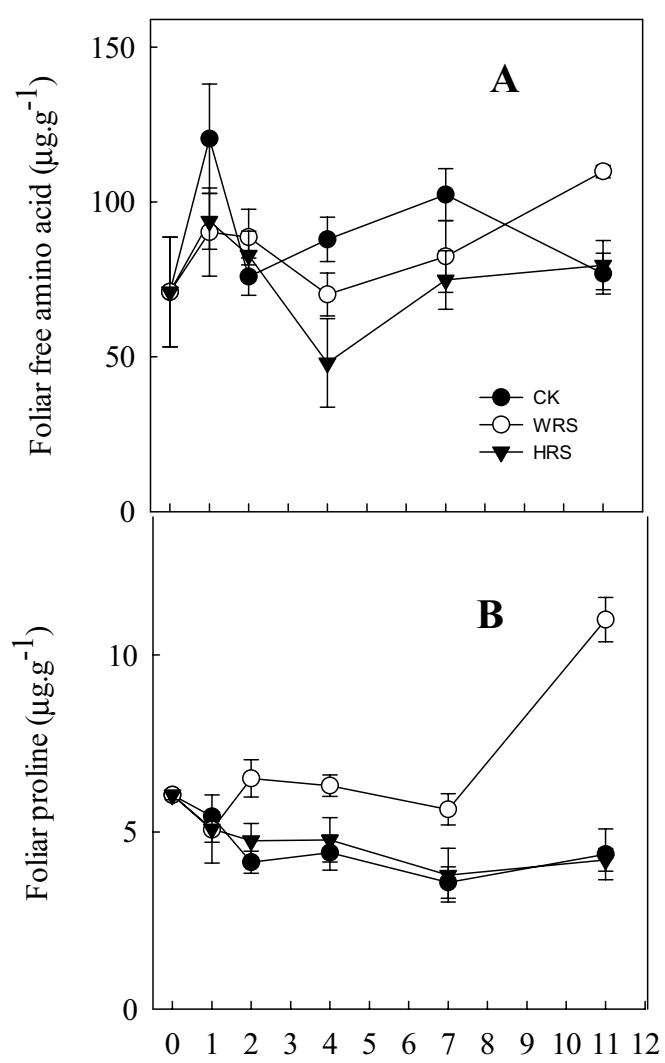

Time after treatment (d)

Fig. 6. Foliar free amino acid (A) and proline (B) concentration of micropropagated apple plants under half root drought stress (HRS) and whole root drought stress (WRS) when compared with control (CK). The concentration is expressed on a fresh weight basis. Each point is mean $\pm \operatorname{SE}(n=4)$.

usually result from drought stress applied to whole roots in apple (Li and Li, 2005; Rufty et al., 1988), grape (Vitis vinifera L.) (Rodrigues et al., 1993), and peach [Prunus persica (L.) Batsch] (Chai et al., 2001; Escobar-Gutiérrez et al., 1998). The results obtained in this study show that drying half the root system influenced Pn in micropropagated apple plants (Fig. 5A), although $\Psi_{\text {pd }}$ of HRS plants did not differ from that of CK plants with significant differences between them during the daytime (Fig. 1A-B). Leaf $\mathrm{Pn}, \mathrm{g}_{\mathrm{s}}$, and $\mathrm{Tr}$ decreased significantly after half or the whole root system of apple plants were subjected to drought stress (Fig. $5 \mathrm{~A}-\mathrm{C}$ ). Usually the presence of $\mathrm{NO}_{3}^{-}$not only triggers changes in the $\mathrm{NO}_{3}$ - assimilation pathway but it also reprograms several pathways of carbon metabolism (Krapp et al., 2002). In the presence of $\mathrm{NO}_{3}^{-}$, carbohydrate synthesis decreases and more carbon is converted via glycolysis to phosphoenolpyruvate and enters organic acid metabolism (Krapp et al., 2002). In 'Gala' apple, Pn and $g_{s}$ decreased with decreasing leaf $N$, and the activities of Rubisco and other photosynthesis-related enzymes were limited by $\mathrm{N}$ limitation (Chen and Cheng, 2004). Also, a close relationship was found between foliar $\mathrm{N}$ content and $\mathrm{CO}_{2}$ assimilation in 'Fuji' apple (Cheng and Fuchigami, 2000a, 2000b). However, there were no significant differences in foliar $\mathrm{NO}_{3}^{-}$(Fig. 2A) and $\mathrm{NH}_{4}{ }^{+}$concentration (Fig. 4A) between either drought stress treatment and $\mathrm{CK}$, and no significant correlation between foliar $\mathrm{NO}_{3}$ - concentration and photosynthesis was found in the present study. It is possible that the response of leaf photosynthesis and related photosynthetic parameters would not be influenced directly 


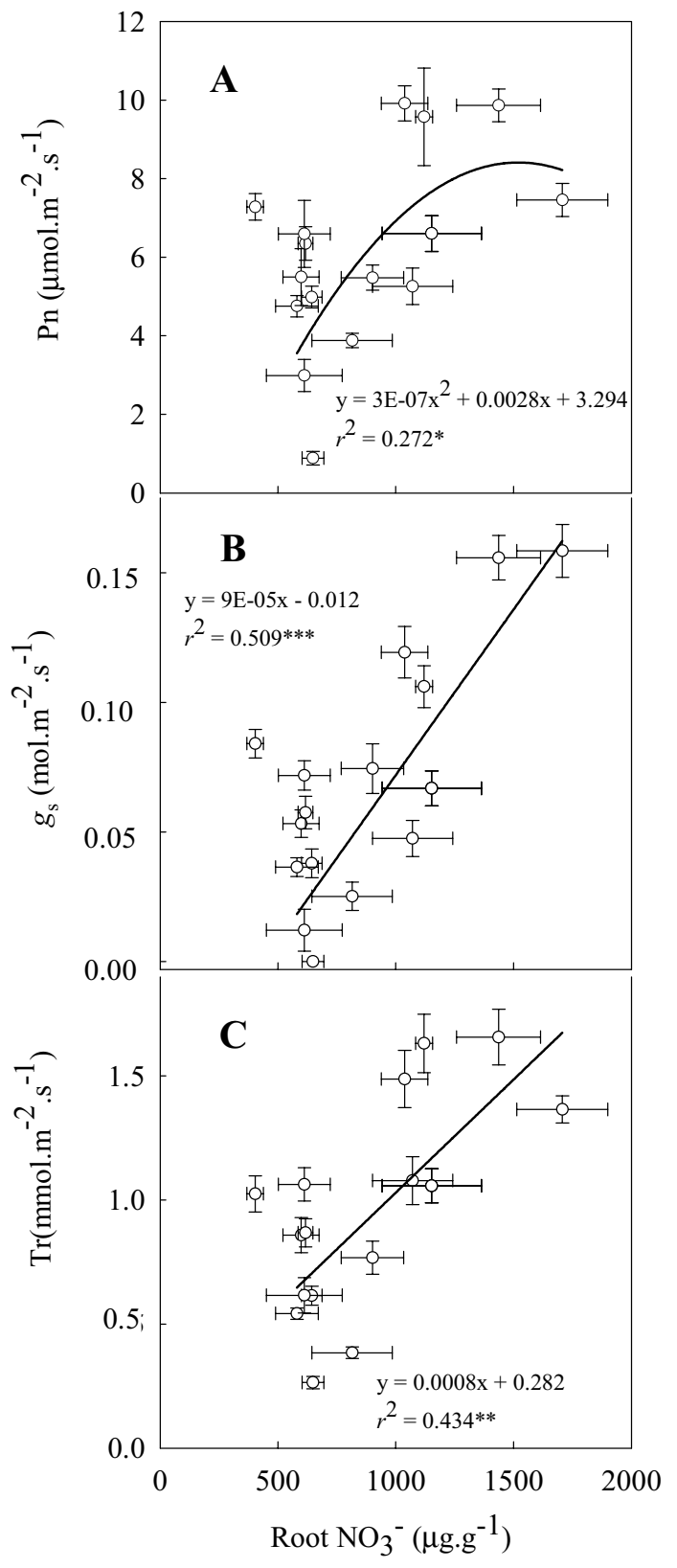

Fig. 7. Correlations between root $\mathrm{NO}_{3}^{-}$concentration and leaf net photosynthesis $(\mathrm{Pn})(\mathbf{A})$, stomatal conductance $\left(\mathrm{g}_{\mathrm{s}}\right)(\mathbf{B})$, and transpiration rate $(\mathrm{Tr})(\mathbf{C})$ of apple plants subjected to drought stress, respectively. As regards $\mathrm{NO}_{3}$ - concentration of half root drought stress, only the data obtained in the stressed roots were used in regression analysis. Each point is mean $\pm \mathrm{SE}$ for root $\mathrm{NO}_{3}{ }^{-}$concentration (horizontal, $\mathrm{n}=4$ ) and the dependent variables (vertical, $\mathrm{n}=4$ ). The asterisks *,**, and *** indicate significance at $0.05,0.01$, and 0.001 , respectively.

by changes in foliar $\mathrm{NO}_{3}{ }^{-}$and $\mathrm{NH}_{4}{ }^{+}$concentration under drought stress. However, both HRS and WRS induced significantly lower root $\mathrm{NO}_{3}{ }^{-}$concentration in stressed roots as early as the day $1,4 \mathrm{~h}$ after drought stress treatments were initiated (Fig. 2B), as well as higher $\mathrm{NH}_{4}{ }^{+}$concentration in stressed roots from day 7 to 11 after plants were subjected to drought stress (Fig. 4B). Furthermore, $\mathrm{Pn}, \mathrm{g}_{\mathrm{s}}$, and Tr were each positively correlated only with root $\mathrm{NO}_{3}$ concentration (Fig. 7A-C). This correlation may simply reflect the fact that water stress affected both $\mathrm{NO}_{3}$ - concentration in roots and leaf gas exchange in the same direction.
Though HRS affected root $\mathrm{NO}_{3}-$ metabolism, its negative impact on photosynthesis was not as large as that of WRS. The negative influence on photosynthesis from $\mathrm{NO}_{3}$ - metabolism in the stressed root may have been compensated by normal $\mathrm{NO}_{3}$-metabolism in the unstressed roots. This may be why no apparent nitrogen-related metabolic changes were observed in leaves of micropropagated apple plants under HRS, such as free amino acid (Fig. 6A) and proline accumulation (Fig. 6B). Though no correlation between foliar $\mathrm{NO}_{3}$ - concentration and photosynthesis was found, it would be useful to know if specific localization of $\mathrm{NO}_{3}{ }^{-}$in certain cells or different compartments of a given cell may be taking part in regulating photosynthesis and related processes.

In conclusion, drought stress applied to half root system can induce a similar effect on leaf Pn and nitrogen nutrition to that resulted from whole root drying in apple plants in this study although there were considerable differences in water status between the plants subjected to half and whole root drying. Both HRS and WRS decreased significantly leaf $\mathrm{Pn}, \mathrm{g}_{\mathrm{s}}$, and $\mathrm{Tr}$, as well as the $\mathrm{NR}$ and $\mathrm{NO}_{3}{ }^{-}$concentration in stressed root. Quick response of HRS plants to $g_{s}$ and $\mathrm{Tr}$ confirms the advantage of economizing water use of trees by using localized irrigation technique. Moreover, limitation in use of assimilates and nitrogen nutrition, represented by low $\mathrm{Pn}$ and $\mathrm{NO}_{3}$ - concentration in stressed roots, of the HRS plants in this study may explain in part why the fruit trees in the field under localized irrigation have decreased vegetative growth when compared with those under flood irrigation.

\section{Literature Cited}

Azedo-Silva, J., J. Osório, F. Fonseca, and M.J. Correia. 2004. Effects of soil drying and subsequent re-watering on the activity of nitrate reductase in roots and leaves of Helianthus annuus. Functional Plant Biol. 31:611-621.

Bates, L.S., S.P. Waldren, and I.D. Teare. 1973. Rapid determination of free proline for water-stress studies. Plant Soil 39:205-207.

Bradford, M.M. 1976. A rapid and sensitive method for the quantitation of microgram quantities of protein utilizing the principle of protein-dye binding. Anal. Biochem. 72:248-254.

Bryla, D.R., T.J. Trout, J.E. Ayars, and R.S. Johnson. 2003. Growth and production of young peach trees irrigated by furrow, microjet, surface drip, or subsurface drip systems. HortScience 38:1112-1116.

Buljovcic, Z. and C. Engels. 2001. Nitrate uptake ability by maize roots during and after drought stress. Plant Soil 229:125-135.

Chai, C.L., S.H. Li, and Y.C. Xu. 2001. Carbohydrate metabolism in peach leaves during water stress and after stress relief. Plant Physiol. Commun. 37:495-498.

Chandrasekar, V., R.K. Sairam, and G.C. Srivastava. 2000. Physiological and biochemical responses of hexaploid and tetraploid wheat to drought stress. J. Agron. Crop Sci. 185:219-227.

Chen, L.S. and L. Cheng. 2004. Photosynthetic enzymes and carbohydrate metabolism of apple leaves in response to nitrogen limitation. J. Hort. Sci. Biotechnol. 79:923-929.

Cheng, L. and L.H. Fuchigami. 2000a. $\mathrm{CO}_{2}$ assimilation in relation to nitrogen in apple leaves. J. Hort. Sci. Biotechnol. 75:383-387.

Cheng, L. and L.H. Fuchigami. 2000b. Rubisco activation state decreases with increasing nitrogen content in apple leaves. J. Expt. Bot. 51:1687-1694.

Correia, M.J., F. Fonseca, J.A. Silva, C. Dias, M.M. David, I. Barrote, M.L. Osório, and J. Osório. 2005. Effects of water deficit on the activity of nitrate reductase and content of sugars, nitrate and free amino acids in the leaves and roots of sunflower and white lupin plants growing under two nutrient supply regimes. Physiol. Plant. 124:61-70.

Davies, W.J., M.A. Bacon, D.S. Thompson, W. Sobeih, and L.G. Rodríguez. 2000. Regulation of leaf and fruit growth in plants growing in drying soil: Exploitation of the plants' chemical signaling system 
and hydraulic architecture to increase the efficiency of water use in agriculture. J. Expt. Bot. 51:1617-1626.

Demšar, J., J. Osvald, and D. Vodnik. 2004. The effect of light-dependent application of nitrate on the growth of aeroponically grown lettuce (Lactuca sativa L. ). J. Amer. Soc. Hort. Sci. 129:570-575.

Escobar-Gutiérrez, A.J., B. Zipperlin, F. Carbonne, A. Moing, and J.P. Gaudillère. 1998. Photosynthesis, carbon partitioning and metabolite content during drought stress in peach seedling. Austral. J. Plant Physiol. 25:197-205.

Ferrario-Méry, S., M.H. Valadier, and C.H. Foyer. 1998. Over expression of nitrate reductase in tobacco delays drought-induced decreases in nitrate reductase activity and mRNA. Plant Physiol. 117:293-302.

Foyer, C.H. and G. Noctor. 2002. Photosynthetic nitrogen assimilation: Inter-pathway control and signaling, p. 1-22. In: C.H. Foyer and G. Noctor (eds.). Photosynthetic nitrogen assimilation and associated carbon and respiratory metabolism. Kluwer Academic Publishers, Dordrecht, The Netherlands.

Foyer, C.H., M.H. Valadier, A. Migge, and T.W. Becker. 1998. Droughtinduced effects on nitrate reductase activity and mRNA on the coordination of nitrogen and carbon metabolism in maize leaves. Plant Physiol. 117:283-292.

Gawronska,H.,A. Deji,H. Sakakibara, and T. Sugiyama. 2003. Hormonemediated nitrogen signaling in plants: Implication of participation of abscisic acid in negative regulation of cytokinin-inducible expression of maize response regulator. Plant Physiol. Biochem. 41:605-610.

Goupil, P., D. Loncle, N. Druart,A. Bellettre, and S. Rambour. 1998. Influence of ABA on nitrate reductase activity and carbohydrate metabolism in chicory roots (Cichorium intybus L.). J. Expt. Bot. 49:1855-1862.

Grasmanis, V.O. and D.J.D. Nicholas. 1967. A nitrate reductase from apple roots. Phytochemistry 1967:217-218.

Heckathorn, S.A., E.H. DeLucia, and R.E. Zielinski. 1997. The contribution of drought-related decrease in foliar nitrogen concentration to decrease in photosynthesis capacity during and after drought in prairie grasses. Physiol. Plant. 101:173-182.

Jiang, R., Y.E. Jin, and G.Q. Wang. 2003. Determination of nitrite and nitrate in vegetables and fruits by ion chromatography. Anal. Instrument. 29-31

Krapp, A., M.S. Ferrario, and B. Touraine. 2002. Nitrogen and signaling, p. 205-225. In: C.H. Foyerand G. Noctor (eds.). Photosynthetic nitrogen assimilation and associated carbon and respiratory metabolism. Kluwer Academic Publishers, Dordrecht, The Netherlands.

Lee, H.J. and J.S. Titus. 1992. Nitrogen accumulation and nitrate reductase activity in MM. 106 apple trees as affected by nitrate supply. J. Hort. Sci. 67:273-281.
Li, S.H., J.G. Huguet, and C. Bussi. 1989. Irrigation scheduling in a mature peach orchard using tensiometers and dendrometers. Irr. Drainage Systems 3:1-12.

Li, T.H. and S.H. Li. 2005. Leaf responses of micropropagated apple plants to water stress: Nonstructural carbohydrate composition and regulatory role of metabolic enzyme. Tree Physiol. 25:495-504.

Loveys, B.R., P.R. Dry, M. Stoll, and M.G. McCarthy. 2000. Using plant physiology to improve the water use efficiency of horticultural crops. Acta Hort. 573:187-197.

Michel, B.E. and M.R. Kaufmann. 1973. The osmotic potential of polyethylethylene glycol 6000. Plant Physiol. 51:914-916.

Parsons, R. and R.J. Sunley. 2001. Nitrogen nutrition and the role of root-shoot nitrogen signaling particularly in symbiotic systems. J. Expt. Bot. 52:435-443.

Punthakey, J.F. 1984. Stomatal response to leaf water potential of drip irrigated peach. Trans. Amer. Soc. Agr. Eng. 27:1442-1450.

Rodrigues, M.L., M.M. Chaves, R. Wendler, M.M. David, W.P. Quick, R.C. Leegood, M. Stitt, and J.S. Pereira. 1993. Osmotic adjustment in water stressed grapevine leaves in relation to carbon assimilation. Austral. J. Plant Physiol. 20:309-321.

Rufty, T.W., S.C. Huber, and R.J. Volk. 1988. Alterations in leaf carbohydrate metabolism in response to nitrogen stress. Plant Physiol. 88:725-730.

Scheible, W.R., A.G. Fontes, M. Lauerer, B.M. Rober, M. Caboche, and M. Stitta. 1997. Nitrate acts as a signal to induce organic acid metabolism and repress starch metabolism in tobacco. Plant Cell 9:783-798.

Scholander, P.F., H.T. Hammel, E.A. Hemmingsen, and E.D. Bradstreet. 1964. Hydrostatic pressure and osmotic potential in leaves of mangroves and some other plants. Proc. Natl. Acad. Sci. USA 52:119-125.

Shangguan, Z.P., M.A. Shao, and J. Dyckmans. 2000. Nitrogen nutrition and water stress effects on leaf photosynthetic gas exchange and water use efficiency in winter wheat. Environ. Expt. Bot. 44:141-149.

Tang, Z.C. 1999. Methods in modern plant physiology. Science Press, Beijing, China. (in Chinese).

Tischner, R. 2000. Nitrate uptake and reduction in higher and lower plants. Plant Cell Environ. 24:1005-1024.

Xu, C.X. 1999. Biological response of Redchief Delicious apple under drip irrigation and the related physiological ecological mechanism. M.A. Diss. 35-37. Gansu Agricultural University, Lanzhou, China. (in Chinese)

Zhu, H., M.C. Lamb, C.L. Butts, and P.D. Blankenship. 2004. Improving peanut yield and grade with surface drip irrigation in undulating fields. Trans. Amer. Soc. Agr. Eng. 47:99-106. 